\title{
STUDY ON MECHANISM OF BACK-SILTATION IN THE DEEP-DRAFT WATERWAY OF THE YANGTZE ESTUARY, AND EVALUTION OF ENGINEERING MEASURE
}

\author{
Gao $\operatorname{Min}^{1}$ and Wan Yuanyang ${ }^{2}$
}

\begin{abstract}
Since the $92.2 \mathrm{~km}$-long, 350m-wide and $-12.5 \mathrm{~m}$-deep draft channel was successfully achieved in the South Channel and the North Passage in the year 2010, high siltation was found to temporally take place in the wet seasons, and spatially concentrate in the middle reach of the North Passage of the Yangtze Estuary. Field survey and numerical modeling were carried out to study the mechanism of back-siltation in the channel. The study found that the sediment from the South Training Dike is a main sediment source for the back-siltation in wet seasons as well as reveals the mechanism of the flow and sediment transportation and siltation in the North Passage. Then the Sand Retaining Dike Heightening Project was proposed and conducted in 2016. Finally, evaluation of the engineering effect is proposed and the project is proved to be effective.
\end{abstract}

Keywords: The Deep-draft Waterway; Yangtze Estuary; back-siltation; measurement; numerical modeling

\section{INTRODUCTION}

China's coasts are on the East China Sea, Korea Bay, Yellow Sea, and South China Sea. Understanding the interconnected sediment physical processes of erosion, transportation and deposition of a coastal and oceanic system is of crucial importance for engineering safety and local human social development(Geyer et al., 2010; Kirby, 2011; Mehta, 2014). During the past engineering applications and practices in China, including port and harbor projects, land reclamation, dam and reservoir constructions, navigational channel development, environmental protection and disaster prevention, many effective experiences and fundamental understanding have been achieved regarding sediment transport and morphodynamics (Burchard et al., 2010; Cheng et al., 2009; Geyer and Farmer, 1989; Manning, 2004; Uncles et al., 1990; van Maren et al., 2015; Wan, 2015; Wang et al., 2014; Winterwerp, 2011).

Since the $92.2 \mathrm{~km}$-long, 350m-wide and $-12.5 \mathrm{~m}$-deep draft channel was successfully achieved in the South Channel and the North Passage in the year 2010, high siltation was found to temporally take place in the wet seasons, and spatially concentrate in the middle reach of the North Passage, where is consistent with the location of the traditional turbidity maximum zone (TMZ) of the Yangtze Estuary (Fig. 1). The data from 2011 to 2015 show that the average annual siltation in the draft channel reached 80 Million $\mathrm{m}^{3}$ per year (Fig. 2). According to back-siltation data of the channel and the analysis, in South channel and Yuanyuansha reach, the amount of siltation has continued to decline since 2013 with the improvement of local river regime and sediment conditions (Fig. 2). And more than $80 \%$ of the siltation in the North Passage is produced during wet seasons. Therefore, the study is mainly focused on the North Passage during wet seasons, where is the traditional TMZ.

With systematic analysis of the sediment source and comprehensive investigation on the mechanism of the flow and sediment transportation and siltation in the North Passage, this paper reveals a major cause and mechanism of the back-siltation in the middle reach and subsequently discusses several engineering measures proposed to reduce the siltation. The final-selected engineering measure has been implemented quite recently, and the preliminary study shows that desired effect has been produced by the engineering measure.

\footnotetext{
1 Yangtze Estuary Waterway Administration Bureau, MOT, Shanghai 200003, China

2 Shanghai Estuarine and Coastal Science Research Center, Shanghai 201201, China
} 


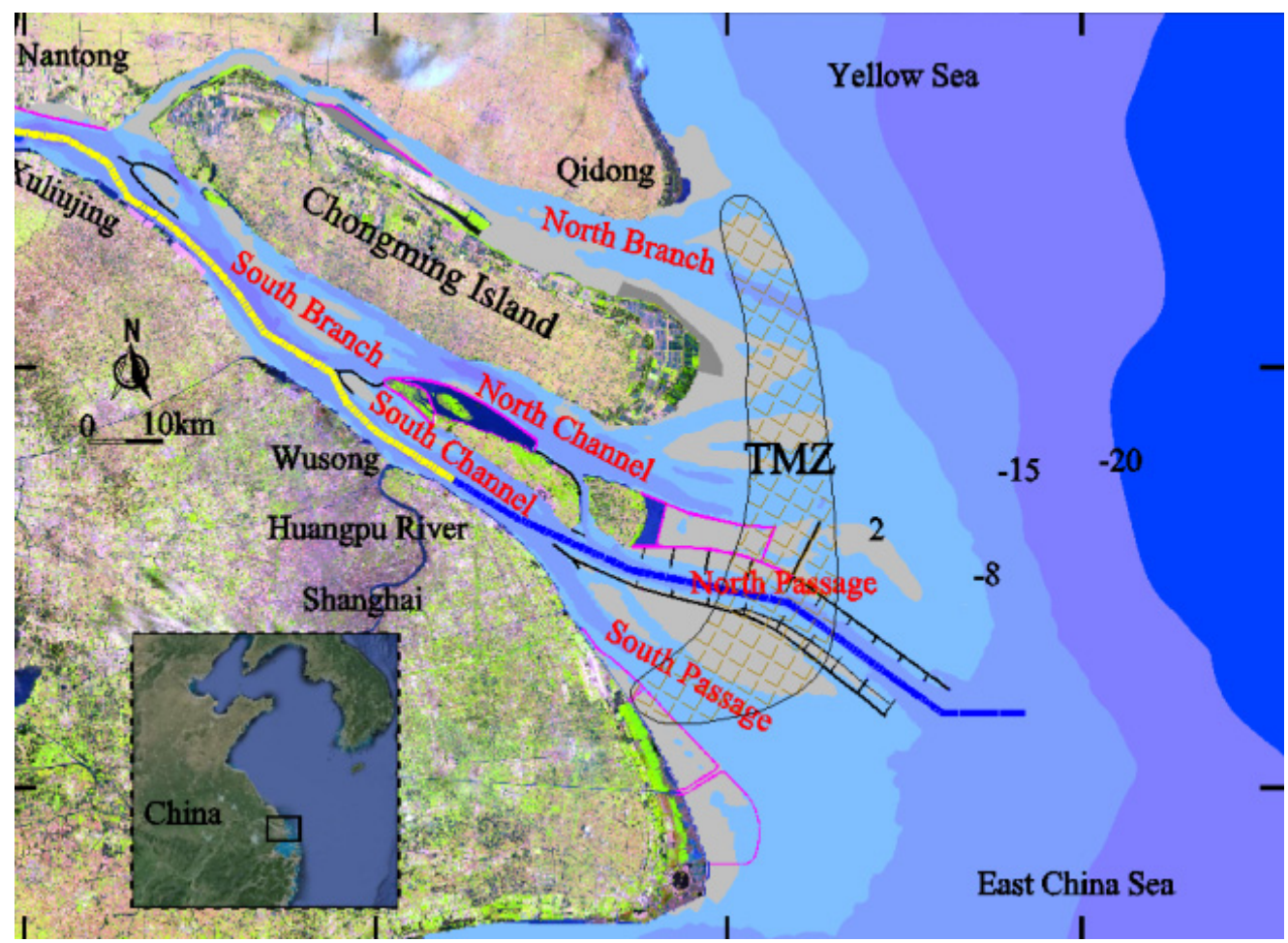

Figure 1. General layout of the Yangtze Estuary. The blue bold line is the $-12.5 \mathrm{~m}$-deep draft channel

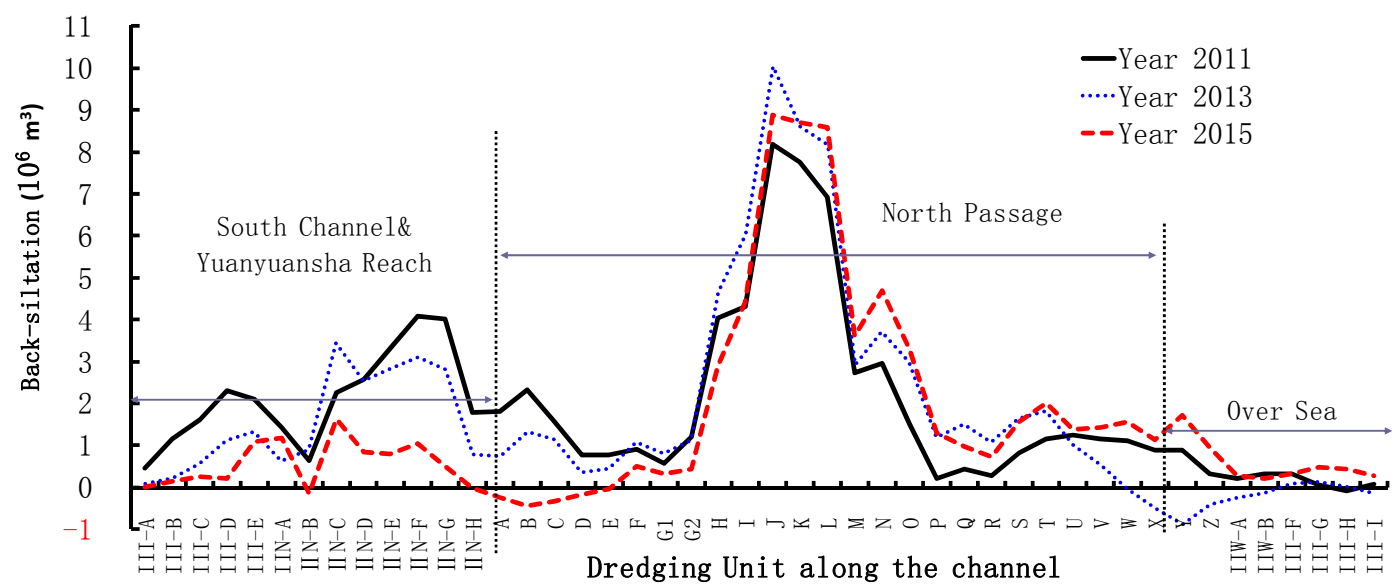

Figure 2. Annual back-siltation along the deep navigation channel, the location of the dredging unit refers Fig.6

\section{METHODS}

\section{Field survey}

Firstly, field survey for measuring the tidal water flux and suspended sediment flux of the North Passage were deployed in the year of 2013 and 2016, respectively. The deployment of the field survey refers Fig. 3. The fluxes of the up and down boundaries are measured by ADCP and water sampling, while the fluxes of the south and north boundaries are determined by OBS and ADV. 


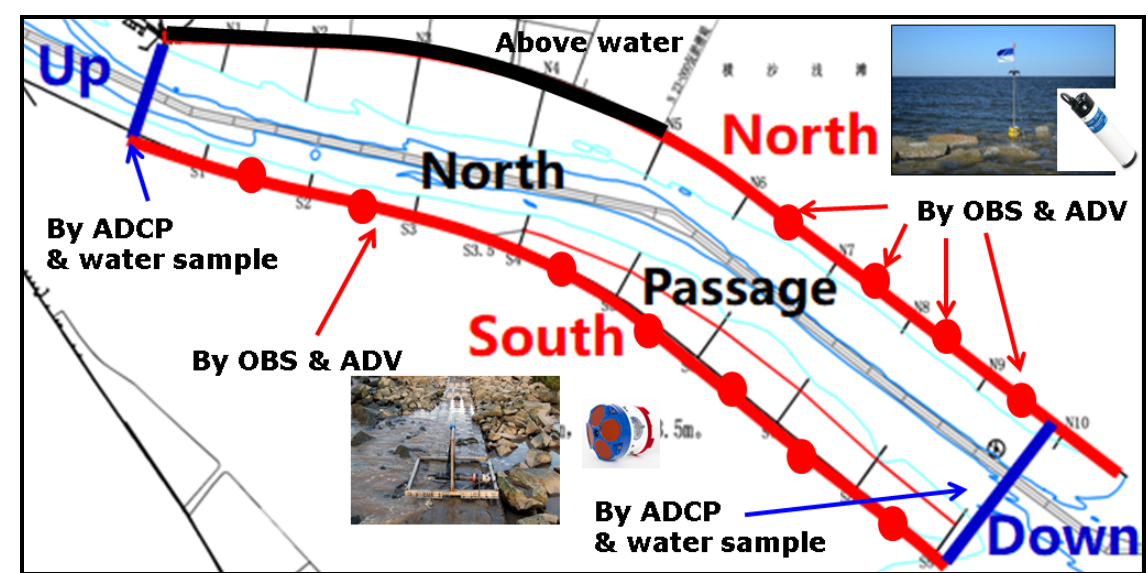

Figure 3. The deployment of the field survey for measuring the tidal water flux and suspended sediment flux of the North Passage.

Secondly, in-situ measurement for hydrodynamics condition in the North Passage were carried out in the 2013 and 2016. Vertical current, salinity, and SSC observations were collected from ten shipborne stations along the channel during both spring and neap tides. Data were collected hourly at six layers within the water column with relative depths of 0.05 (near surface), $0.2,0.4,0.6,0.8$, and 0.95 (near-bed) at each station.

\section{Numerical modeling}

A three-dimensional numerical model is set up to simulate the hydrodynamics, sediment and salinity transport in the Yangtze Estuary with calibration and validation, details see (Wan, 2015; Wan and Wang, 2017). The model was employed to reveal the main sediment source which results in the high siltation in the channel, the main mechanism which governs the spatial and temporal distribution of the siltation, and accordingly preparatory engineering measures to reduce the siltation were proposed.

\section{RESULTS}

\section{Sediment source}

The field data shows that the sediment concentration and amount transported from the South Training Dike during the flood tide are larger than those from other sections, while during the ebb tide little sediment was transported out of North Passage over the South Training Dike. The ratios of sediment transported from upper, lower, south and north sides into North Passage are 1.0:1.16:2.1:0.09 in spring tide Sep. 2013. Due to the fact that the river runoff, mean sea level, tidal range and wave conditions in wet seasons are larger than those of in dry seasons, the sediment flux transported from South Training Dike in wet seasons is much bigger than that in dry seasons(Liu et al., 2011).The sediment from the South Training Dike is a main sediment source for the back-siltation in wet seasons.

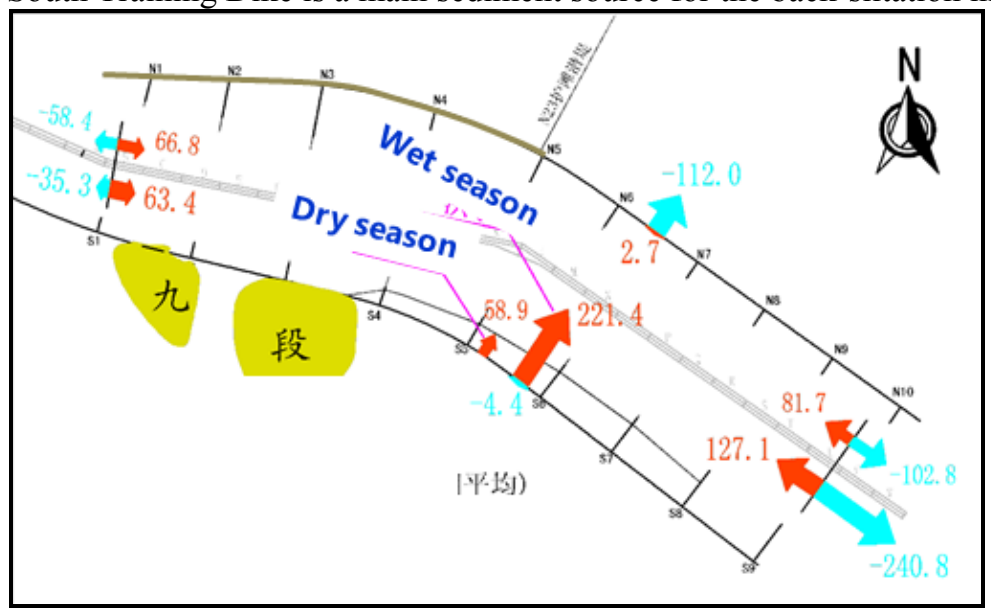

Figure 4. Suspended sediment flux of the North Passage during the wet and dry seasons of 2013. The red arrows denote the sediment fluxes coming into the North Passage, while the blue arrows are the fluxes departing away from the North Passage. 


\section{Mechanism}

The major physical processes for the formation of the estuarine turbidity maximum (ETM) have been investigated. Based on near-bed tripod observation and 3D sedimentation modeling, the main mechanisms of the back-silting in the DNC were preliminarily investigated (ECSRC; 2014). The main phenomenon related to the siltation characteristic is that a high-concentration layer near the bottom is formed in the wet seasons. And, the time of occurrence of the near bed high-concentration layer is coincide with the period of low currents intensity in the middle reach of the channel, which is benefit to sedimentation in this reach. The mechanism related to this phenomenon is associated with the flowsediment interaction, which contains (1) density stratification, (2) turbulence damping and (3) flocculation.

The salinity \& SSC-induced baroclinic pressure gradient is one of the dominant factors that control variation of vertical velocity structure. Once the internal flow structure is changed, the up-estuary fluxes of sediment and salinity are enhanced near the bottom. Thus, the accumulation of denser materials near the convergent area (salt front) results in density stratification. The vertical density gradient of the stratified flow further produces a buoyancy effect on the turbulence, which suppresses the vertical mixing of momentum and materials, and finally, a high-concentration layer near the bottom is formed due to the turbulence damping.

The presence of salt and suspended particulate matter (SPM) in water column increases mixture density, resulting in longitudinal density variations and baroclinic pressure gradient forcing (Wan et al., 2014; $\mathrm{Wu}$ et al., 2012). The vertical gradient of fluid density creates a stratified water column and introduces buoyancy effect on turbulence, damping the flow turbulence (Wang et al., 2013). The SSCand salinity- induced stratification produces a stratified bottom boundary layer, altering the logarithmic velocity profile near the bottom and reducing drag coefficient (Song and Wang, 2013; Wang et al., 2011).

With their cohesive nature, fine sediments are prone to aggregation and formation flocculated network structures (flocs) during the settling process, introducing distinct flocculation acceleration and hindered settling phenomenon (Guo and He, 2011; Shao et al., 2011). During the wet seasons, the higher water temperature, higher SSC will introduce higher sedimentation rate (Fig.5).

The above-mentioned mechanisms are closely associated with channel siltation in the North Passage.

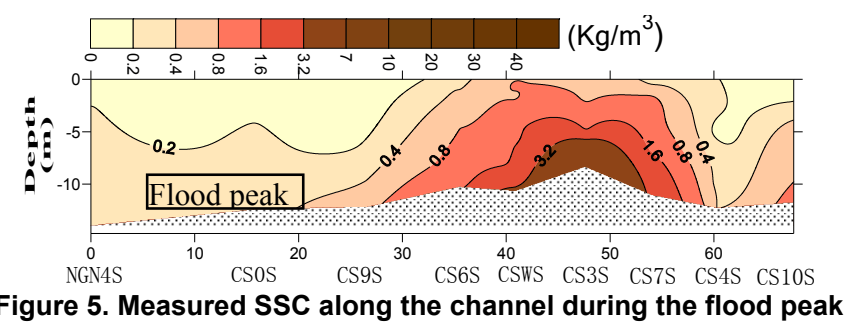

\section{Engineering solution}

Based on the measured data and numerical modeling result, an engineering project (Fig. 6) was proposed to reduce the channel siltation in the Deepwater Navigation Channel. With the aim to decrease the sediment flux transported from the South Dike, then reduce the SSC in the North Passage and finally reduce the back-siltation in the channel, the elevation of the South Dike should be increased. In order to optimize the flow and sediment transport in the North Passage, a number of engineering scenarios including different location and elevation of the South Dike have been examined. Through numerical simulation and physical process-based scaled model studies, Sand Retaining Dike Heightening Project was proposed. The elevation of the existing dike from Groin S4 to Groin S8 was raised to $+3.5 \mathrm{~m}$. Meanwhile the dike was further extended to Groin S9 with elevation up to $+3.5 \mathrm{~m}$ (Fig. 6 ). According to the $3 \mathrm{D}$ numerical model prediction, the amount of siltation in the channel after the project will be reduced by $10 \%$ (Fig. 7). 


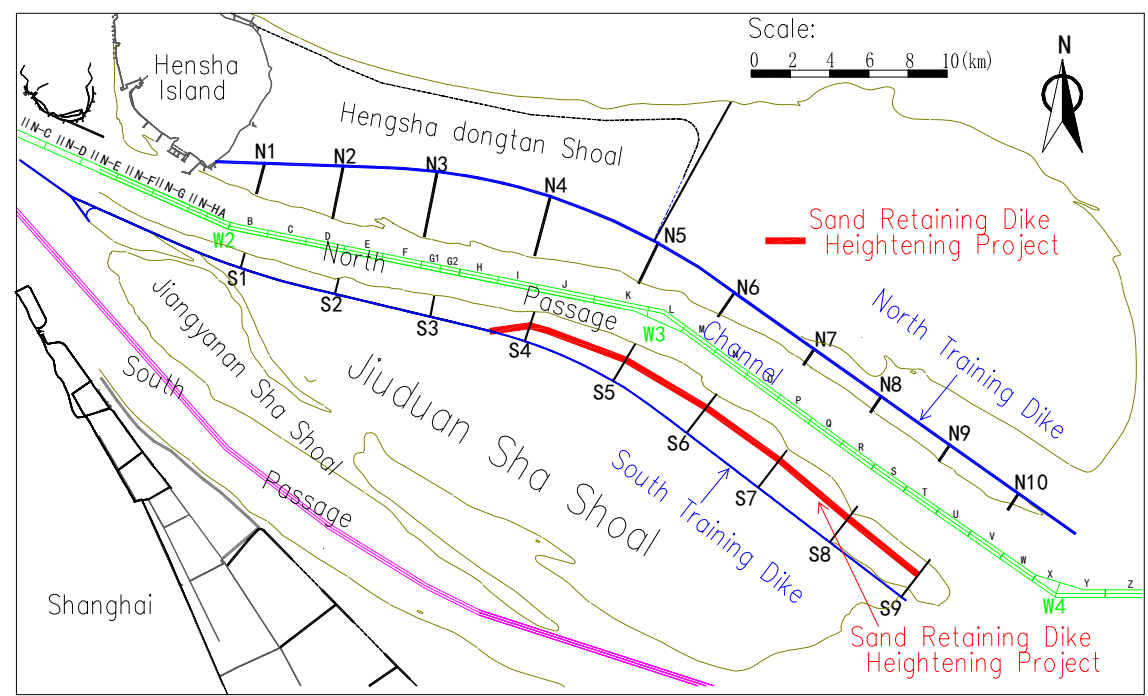

Figure 6. The general layout of the Sand Retaining Dike Heighting Project.
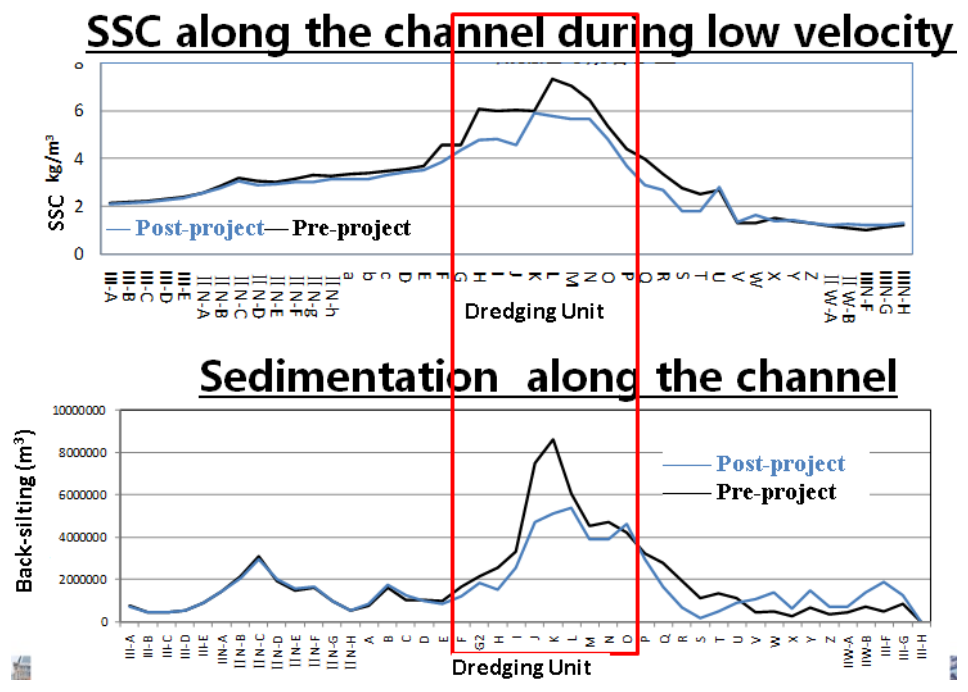

Figure 7. Modeled the SSC and sedimentation along the channel before and after the project.

\section{Engineering effect}

The final-selected engineering measure was constructed in 2016. In-situ monitoring of the Hydroand sediment dynamics, and river bed morphology evolution showed that the natural condition for channel maintenance have been expectedly improved after the project.

(1) The tide flow direction in the middle and lower reaches of the North Passage after the project is smoother than that before the project, and the transverse flow is weakened. Fig. 8 is the measured data.

(2) The sediment transported from the South Dike is declined more than $70 \%$, and the SSC along North Passage is decreased by about $30 \%$ after the project (Fig. 9).

(3) Compared with the condition in 2015 before the project, the amount of siltation in the North Passage in 2017 reduced about 12.7\%, which is greater than the numerical prediction (Fig. 10).

As a result, the desired effect of the engineering measure has been successfully reached. 


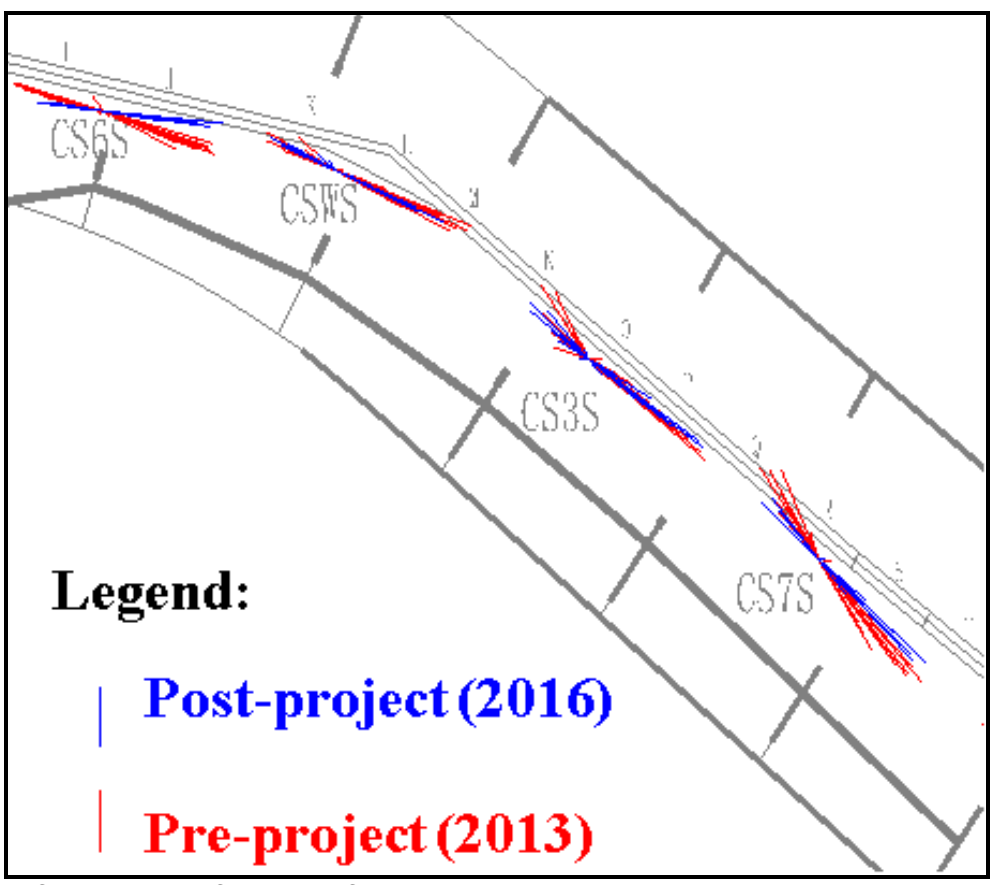

Figure 8. Measured flow roses before and after the project.

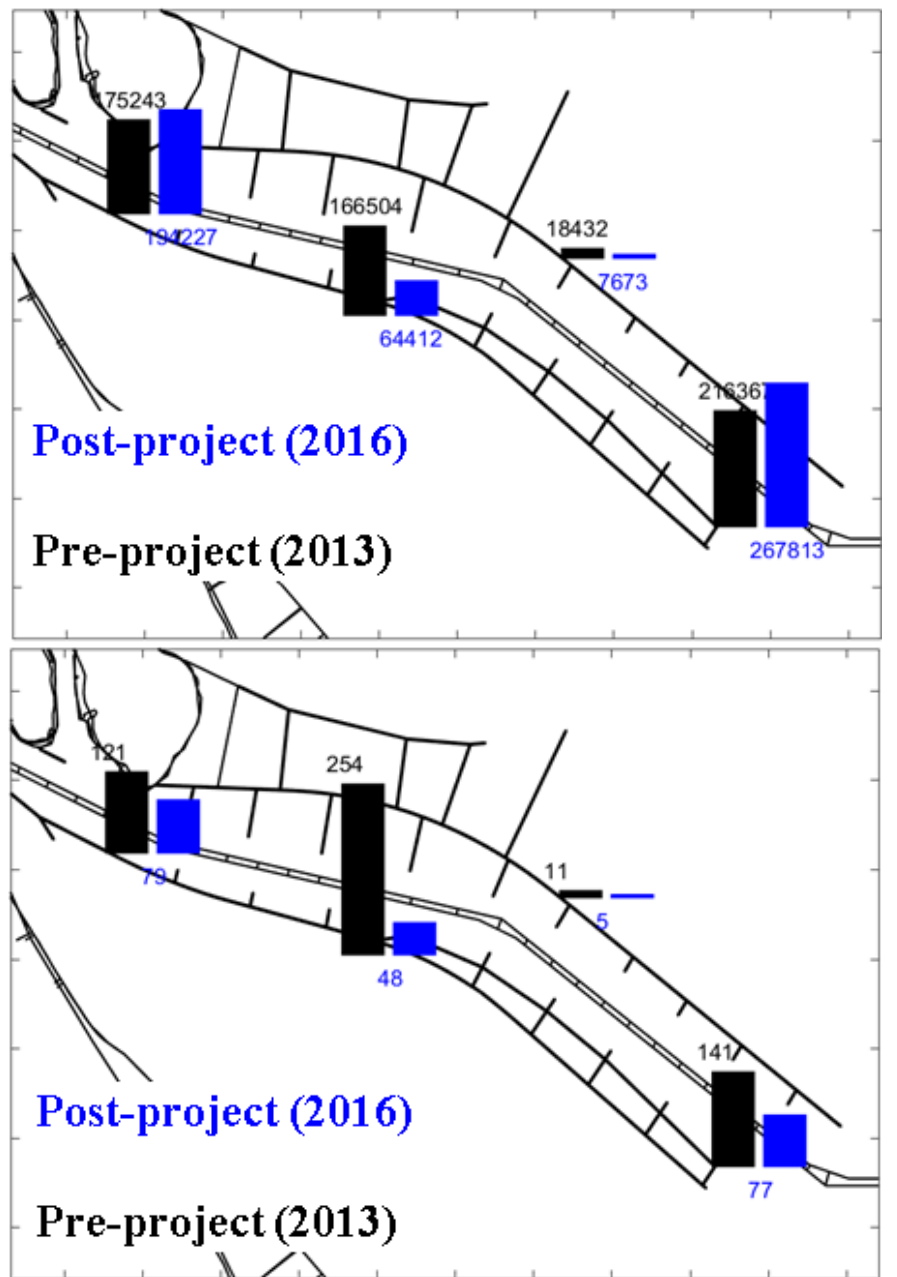

Figure 9. Measured tidal water (upper) and sediment (lower) fluxes before and after the project. 


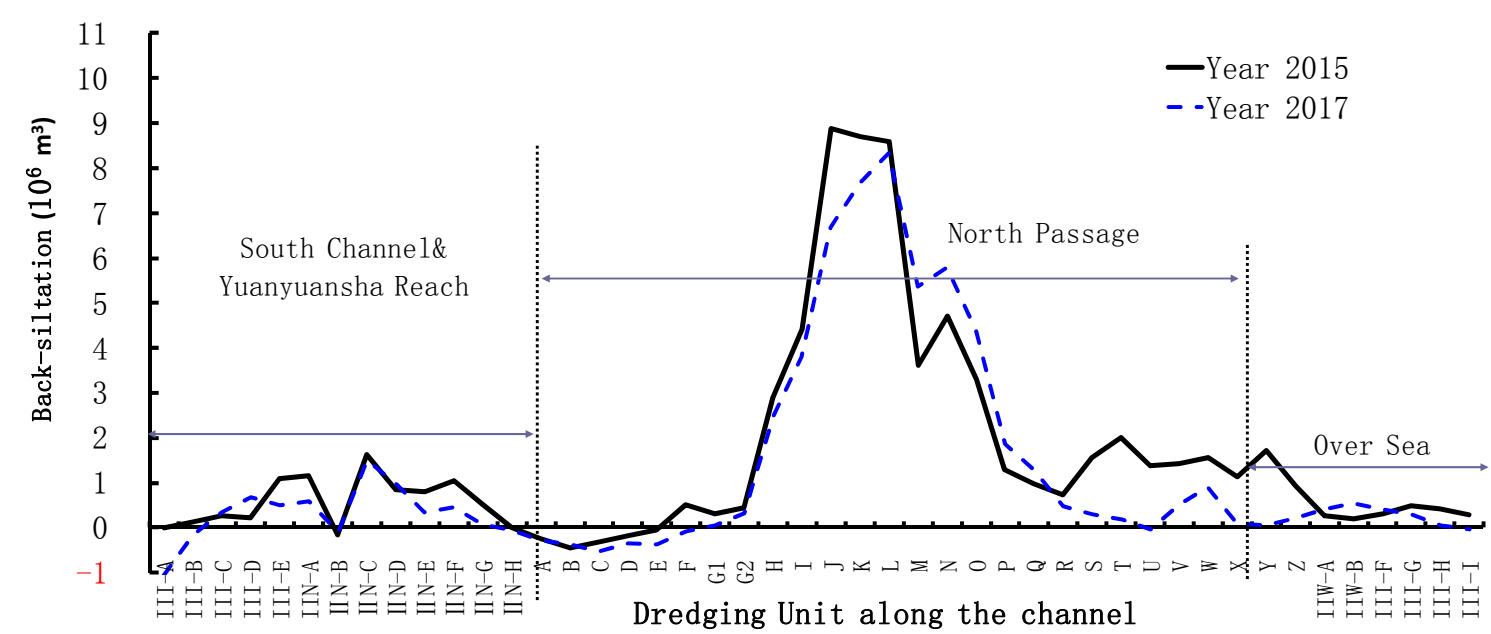

Figure 10. Measured yearly channel sedimentation before and after the project.

\section{CONCLUSION}

The study shows the spatial and temporal distribution characteristics of the back-siltation in the deep-draft channel of the Yangtze Estuary. High siltation occurs in the middle and lower reach of the North Passage during wet seasons. Hydrodynamics, salinity and sediment transport within the TMZ results in salinity and SSC stratification, turbulence damping jointly contribute to the main mechanism which governs back-siltation of the channel. During flood tides, the sediment flux from the South Dike becomes a significant component of the source of back-siltation in wet seasons. The selected engineering scenario was carried out and proved to be effective.

\section{ACKNOWLEDGMENTS}

This study is jointly supported by the National Key R\&D Program of China under grant no. 2017YFC0405403 and National Natural Science Foundation of China under grant no. 41506108.

\section{REFERENCES}

Burchard, H., Hetland, R.D., Schulz, E., Schuttelaars, H.M., 2010. Drivers of Residual Estuarine Circulation in Tidally Energetic Estuaries: Straight and Irrotational Channels with Parabolic Cross Section. Journal of Physical Oceanography 41 (3), 548-570.

Cheng, P., Wilson, R.E., Chant, R.J., Fugate, D.C., Flood, R.D., 2009. Modeling Influence of Stratification on Lateral Circulation in a Stratified Estuary. Journal of Physical Oceanography 39 (9), 2324-2337.

ECSRC, 2014. Mechanisms of the sedimentation in the $-12.5 m$ deepwater navigational channel of the Yangtze Estuary, Report. Shanghai Estuarine and Coastal Science Center. pp. 187. (in Chinese)

Geyer, W.R., Farmer, D.M., 1989. Tide-Induced Variation of the Dynamics of a Salt Wedge Estuary. Journal of Physical Oceanography 19 (8), 1060-1072.

Geyer, W.R., Lavery, A.C., Scully, M.E., Trowbridge, J.H., 2010. Mixing by shear instability at high Reynolds number. Geophysical Research Letters 37 (22), L22607.

Guo, L., He, Q., 2011. Freshwater flocculation of suspended sediments in the Yangtze River, China. Ocean Dynamics 61 (2), 371-386.

Kirby, R., 2011. Minimising harbour siltation-findings of PIANC Working Group 43. Ocean Dynamics 61 (2-3), 233-244.

Liu, G., Zhu, J., Wang, Y., Wu, H., Wu, J., 2011. Tripod measured residual currents and sediment flux: Impacts on the silting of the Deepwater Navigation Channel in the Changjiang Estuary. Estuarine, Coastal and Shelf Science 93 (3), 192-201.

Manning, A.J., 2004. The observed effects of turbulence on estuarine flocculation. Journal of Coastal Research, 90-104.

Mehta, A.J., 2014. An Introduction to Hydraulics of Fine Sediment Transport. World Scientific Publishing Company, Singapore. 
Shao, Y., Yan, Y., Maa, J., 2011. In Situ Measurements of Settling Velocity near Baimao Shoal in Changjiang Estuary. Journal of Hydraulic Engineering 137 (3), 372-380.

Song, D., Wang, X.H., 2013. Suspended sediment transport in the Deepwater Navigation Channel, Yangtze River Estuary, China, in the dry season 2009: 2. Numerical simulations. Journal of Geophysical Research: Oceans 118 (10), 5568-5590.

Uncles, R.J., Ong, J.E., Gong, W.K., 1990. Observations and analysis of a stratification-destratification event in a tropical estuary. Estuarine, Coastal and Shelf Science 31 (5), 651-665.

van Maren, D.S., van Kessel, T., Cronin, K., Sittoni, L., 2015. The impact of channel deepening and dredging on estuarine sediment concentration. Continental Shelf Research 95, 1-14.

Wan, Y., 2015. Multiscale physical processes of fine sediment in an estuary, UNESCO-IHE. Delft University of Technology \& UNESCO-IHE, Delft, The Netherlands, p. 180.

Wan, Y., Gu, F., Wu, H., Roelvink, D., 2014. Hydrodynamic evolutions at the Yangtze Estuary from 1998 to 2009. Applied Ocean Research 47 (0), 291-302.

Wan, Y., Wang, L., 2017. Numerical investigation of the factors influencing the vertical profiles of current, salinity, and SSC within a turbidity maximum zone. International journal of sediment research 32 (1), 20-33.

Wang, Y., Yu, Q., Gao, S., 2011. Relationship between bed shear stress and suspended sediment concentration: annular flume experiments. International journal of sediment research 26 (4), 513523.

Wang, Y.P., Voulgaris, G., Li, Y., Yang, Y., Gao, J., Chen, J., Gao, S., 2013. Sediment resuspension, flocculation, and settling in a macrotidal estuary. Journal of Geophysical Research: Oceans 118 (10), 5591-5608.

Wang, Z.B., Winterwerp, J.C., He, Q., 2014. Interaction between suspended sediment and tidal amplification in the Guadalquivir Estuary. Ocean Dynamics 64 (10), 1487-1498.

Winterwerp, J.C., 2011. Fine sediment transport by tidal asymmetry in the high-concentrated Ems River: indications for a regime shift in response to channel deepening. Ocean Dynamics 61 (2-3), 203-215.

Wu, J., Liu, J.T., Wang, X., 2012. Sediment trapping of turbidity maxima in the Changiiang Estuary. Marine Geology 303-306 (0), 14-25. 